\title{
OPINION
}

\section{Top dogs: wolf domestication and wealth}

\author{
Carlos A Driscoll',2 and David W Macdonald*1 \\ See research article http://www.biomedcentral.com/1741-7007/8/16/
}

\begin{abstract}
A phylogeographic analysis of gene sequences important in determining body size in dogs, recently published in BMC Biology, traces the appearance of small body size to the Neolithic Middle East. This finding strengthens the association of this event with the development of sedentary societies, and perhaps even has implications for the inception of human social inequality.
\end{abstract}

Domestication is a peculiarly human endeavor. The idea that we can learn about ourselves by studying man-made animals is well worn, and considerable effort has been put to the cause $[1,2]$. Although dogs are surely the first domesticate [3], the history regarding the location of their transformation from wolves, and the peoples responsible for it, has been confusing, with genetic evidence pointing to Europe, the Far East and places in between [4-6].

Although other waves of domestication - of chickens, some pigs, llamas, and water buffalo, among others - took place in China and the Americas [7], most of the Western barnyard animals and the cat were domesticated between 12,000 and 8,000 years ago in a region of the Middle East known as the Fertile Crescent [7-10] and are exclusively the product of a sedentary, agricultural, civilized life [7,9,11]. Dogs have been considered as an important exception, the suspicion being that they were domesticated earlier and (perhaps) elsewhere, the product of a still more distant and primitive hunter-gatherer past [12] (Figure 1). The conventional thinking has been that wolves, being highly mobile, were naturally well equipped to follow bands of hunters, of no fixed address, as they roved the end of the Paleolithic in search of game. Protodogs might have scavenged kills left behind by humans as they moved in search of new game, gradually becoming

\footnotetext{
*Correspondence: david.macdonald@zoo.ox.ac.uk

Wildlife Conservation Research Unit, The Recanati-Kaplan Centre, Department of Zoology, University of Oxford, Tubney House, Abingdon Road, Tubney, Abingdon OX13 5QL, UK

Full list of author information is available at the end of the article
}

accustomed to human contact until, over generations, a fully domesticated dog evolved, ready to be put to work [9].

A recent paper in BMC Biology by Gray et al. [13] enables the dog's tale to be viewed through a different prism, bringing genetics into line with archeology, and shining a light (yet again) on the Middle East as the locus of dog domestication, or at least of the appearance of small dogs, and, more importantly, by suggesting that the wolf-dog barrier was jumped at about the time when human communities became settled. This report [13] is noteworthy because it illuminates the origin of small dogs, suggesting a new focus for artificial selection, but also because it provokes an intriguing view of human civilization that puts dogs in the role of not just a treasured companion, but a precursor to wealth and inequality! We present that view in the spirit of speculative musing.

\section{Let sleeping dogs lie}

Although there is little doubt that dogs have a single Eurasian origin from the wolf, Canis lupus, and soon spread to Africa, Europe, Australasia and the Americas [3-6,13-15], interpreting the detail of their molecular history has otherwise been difficult. Phylogeography is an approach that involves the simultaneous study of both temporal and spatial genetic patterns, but phylogeographic patterns that might have illuminated dog origins have been obscured by such factors as their mobility, and that of their human companions, the practice of line breeding (to form 'breeds'), which has isolated and highlighted rare genetic features, and crossing between breeds. The whereabouts of the wolf population that genetically most closely resembles the dog is prima facie evidence for where domestication first occurred. Mitochondria's indeliquescent phylogenetic signal and matrilineal transmission (often resulting in geographically localized patterns) has made mitochondrial DNA (mtDNA) the workhorse of phylogeographic research, including the quest for dog origins or the dog's ancestors. However, despite large sample sizes and sophisticated analytical techniques, mtDNA has proved peculiarly poor at reconstructing dog origins, to the extent that there are almost as many different imputed locations for the dog's origins as there are studies [4-6]. This is, in part, because mtDNA represents only a fraction of the genome, and is 


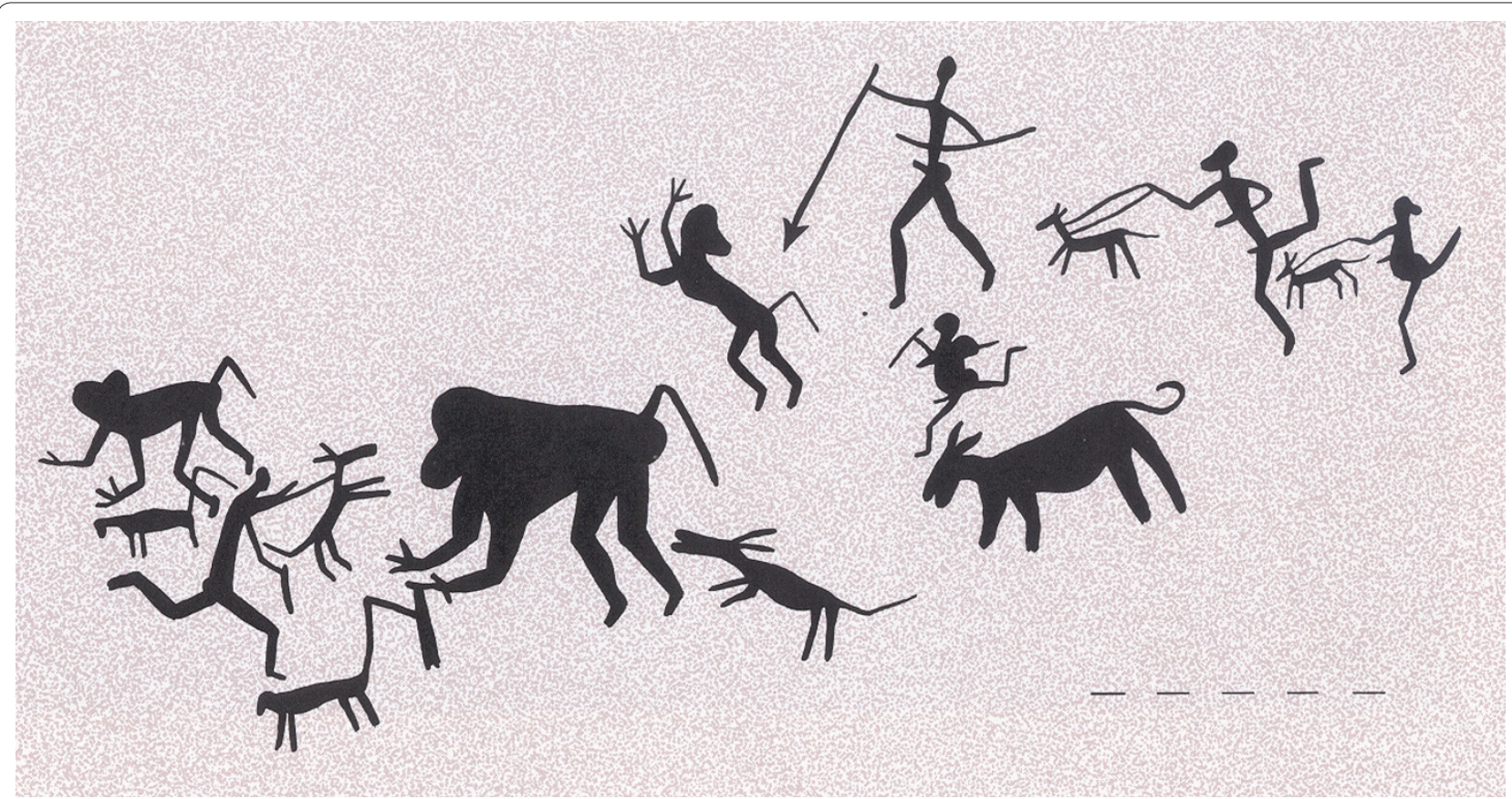

Figure 1. Petroglyphs from Drakensbergs of South Africa illustrating an early hunt with dogs in a manner perhaps analogous to that of the earliest hunter gatherers. Picture used with permission from Vinnicombe P. 1979. People of the Eland: Rock paintings of the Drakenbergs Bushmen as a reflection of their life and thought. Pietermaritzberg: University of Natal Press.

subject to a strong sex bias [4]. Moreover, wolves are highly mobile, resulting in scant geographic patterning in their genetics and, worse, dogs can interbreed with regional native wolf populations $[4,13]$.

Gray et al. [13] use four genomic datasets (single nucleotide polymorphism (SNP), microsatellite, short interspersed nuclear element (SINE) and DNA sequence to investigate the region around the insulin-like growth factor 1 (IGF1) gene on dog chromosome 15, thereby avoiding many of the pitfalls noted above that have obscured dog origins. By imputing phase (that is, the ordering of markers/genes on a particular chromosome of the pair), they characterized a haplotype found in all small dogs (that is dogs of less than $9 \mathrm{~kg}$ ) from schnauzers to Chihuahuas, but not in wild canids nor in most large dog breeds. They deduce that the small dog haplotype (SDH) is derived, arising soon after the domestication of dogs. This SDH is most closely related to that found in wolves from the Middle East, suggesting that region as its origin. Provided that Middle Eastern wolves today most closely resemble Middle Eastern wolves of yesteryear, then a fair inference is that the SDH descends from Middle Eastern wolves.

Although some archaeological estimates for domestication go back as far as 31,000 years ago to central Europe [16], it is more generally agreed that dog domestication occurred between 13,000 and 17,000 years ago (see Table 1 of [9]; because this time is too recent for the molecular clock to tick reliably, estimates must be made on the basis of archaeological excavations alone). These earliest dog remains are found in the Levantine wing of the Fertile Crescent $[17,18]$ from a time when the humans there, the Natufians, were hunter-gatherers, although they lived in permanent or semi-permanent settlements. This narrow transition between Paleolithic nomadic hunter-gathering and the comparatively advanced settled agro-economies of the Neolithic was a critical stage of cultural development and, perhaps, in canine history, was the moment in which wolves crossed the canine Rubicon. This moment of history sets the stage for interpreting the study of Gray et al. [13]. These genetic data may not alone be sufficient to prove that dogs were domesticated solely in the Middle East, although they do very strongly suggest it to be a dominant center. Furthermore, the coincidence in the Middle East of both the origin of human settlement (sedentism) and agriculture on the one hand, and dog diversification on the other, merits a deeper, if declaredly speculative, look.

\section{Puppy love: why wolf domestication?}

There may be increasing consensus on where and when wolves were domesticated, but the how and why are still largely conjectural. But, as the sketch of dog evolution (Figure 2) begins to be colored in, the textures of the overlapping processes of natural and artificial selection are revealed. Domestication is the result of interwoven 


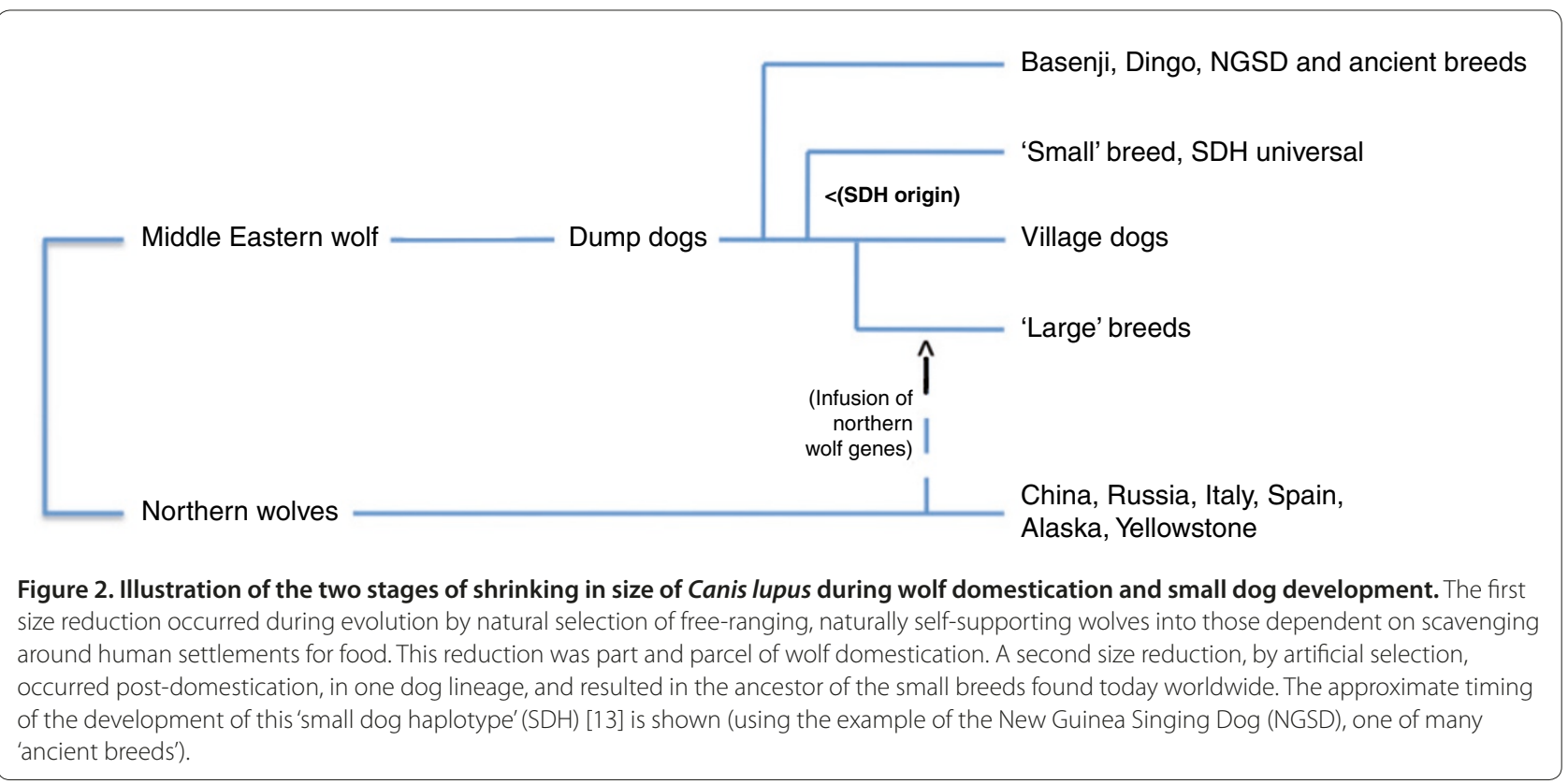

biological and cultural processes [19]. Indeed, the reasons why domestication did not happen in many aboriginal societies were probably cultural. Some have gone so far as to say that animals have to be owned to be domesticated [19], although by more recent understandings this may not be precisely true. Although the burial together of a puppy with a human [17] suggests a strong emotional bond between them, wolves were probably not initially domesticated as pets [20].

The initial association of wolves and humans was doubtless instigated by the wolves $[9,21]$. But, insofar as domestication did not happen overnight, there must have been cultural continuity of wolf tolerance initially and of proto-dog keeping subsequently. A plausible scenario is that proto-domestic wolves were resident scavengers at the rubbish dumps of permanent settlements rather than nomadic camp followers: both wolves and dogs continue in much this role in some places today [22]. Indeed, they perpetuate the general canid dynamic of intraguild competition [23] whereby smaller canids (in this case smaller, domesticated, doggish wolves) can survive the aggression of larger ones (wild wolvish wolves) only with access to a refuge - in this case the umbrella, intended or otherwise, of a companion animal, namely humans. By analogy, and perhaps in a direct parallel, molecular evidence shows that contemporary wild wolf populations the migratory wolves of the tundra compared with territorial populations of the boreal forest - do not interbreed although they overlap geographically for much of the year [24]. These different lifestyles promote reproductive isolation in ways perhaps reminiscent of the divergence of proto-dogs and wolves.
This opening stage of domestication seems to have initiated the shrinking in size of the wolf. The first 'dog' remains in the Near East are considered dogs in part because of their reduced size [25,26]. Small stature presumably reduces energy demand, and perhaps even allows the 'Lupus-light' to fit in more snugly with people than could its lumbering antecedent. To speculate yet more wildly, perhaps intraguild competition then led to small garbage-wolves that became vigilant barkers at the approach of larger and hostile wolves and, in so doing, further divided the population genetically. This series of developments would set up the assortative mating theoretically required for the sympatric divergence of the wolf population [9].

Once in the thrall of humans and their enterprises, dogs became the object of unnatural attention. It seems plausible that the spontaneous occurrence of a 'small' dog, selected on post-zygotic whim favoring the survival of particularly appealing puppies (to quote Ray Coppinger, "freaks can be valuable") encouraged match-making 'kennel clubs' to breed these small dogs with one another, preserving the morphotype $[27,28]$ (this blend of preand post-zygotic selection in domestication is alluded to in [9]). Although the SDH-associated causal mutation for smallness in dogs has not yet been identified [13], given that SDH clusters in toy dogs, it seems to track one form or another of dwarfism. Interestingly, dachshunds and Brittany spaniels (which are not toy dogs and do not carry SDH) also show a strong signature of selection in the gene region that includes IGF, suggesting that the IGF signaling pathway has been the target of artificial selection numerous times through history [27]. Beyond 
the fact that 'small breeds' were perpetuated and spread from their origin in the Middle East across Eurasia, it is this second, saltatory size reduction that indicates a significant degree of human attentiveness. We speculate that these Natufians, having originally selected runts on a whim, thereafter not only perpetuated their whimsy selecting for cuddliness - but also began selecting for pintsized functionality (such as ratting and entering burrows).

\section{The dogged pursuit of wealth}

Being significantly smaller than the competition - the process of 'diminution', as here traced for dogs [13] - is likely to be maladaptive in the wild; this trait was therefore probably selected under the influence of people. This conclusion sheds a quizzical light on human history, provoking a major question regarding the origin of Neolithic civilization. What came first - the social order (divisions of labor and class) or the means of production (agriculture versus hunting-gathering)? One hypothesis holds that the means of production came first; that is, people learned to farm, which led to an accumulation of wealth that in turn promoted the development of a tiered social order [2]. This view generally discounts culture, ascribing success instead to luck in the geographical lottery - some people lived in fertile, resource-rich areas while others did not. But it could have happened the other way around - stable social orders were established first and these were a prerequisite that facilitated domestication and farming. Without denying the necessity of technological innovations, this view weights cultural institutions much more heavily [7].

Dogs are the earliest domesticates, predating barnyard animals by 1,000 to 5,000 years or more [9]. Gray et al. [13] provide evidence that early Middle Eastern dogs segregate for a character, non-adaptive in the wild, that is probably the result of long-term association with humans and must have occurred over many human generations. We can infer from this that these human cultures were sedentary and stable (at least enough to support development of smallness in early dogs), and had some loose cultural concept of tolerance for dogs, if not of caring and ownership of them. This supports the view that those societal institutions presumably required for a long-lasting, stable settlement to function had developed before the domestication of barnyard animals, perhaps even providing the circumstances that enabled those domestications to take place [7]. Domestication is a key feature of the Neolithic Revolution, a suite of cultural innovations and consequences comprising sedentism, an agricultural economy, and complex social arrangements conducive to urban living.

The Neolithic Revolution had many unpredictable consequences, including elaborate politics, runaway population growth, taxes and social inequality. Recently, the foundations of social inequality have been traced to variability in the inter-generational transmission of wealth $[29,30]$. A parent's wealth is the best predictor of offspring's wealth, and the more effective the vertical transmission of wealth, the more pronounced the inequality over generations. Wealth can be material, social or knowledge-based, but material wealth is most transmissible [29]. Thus, economies where material wealth is important are expected to show substantial levels of social inequality.

Material wealth becomes more important as societies progress from hunter-gatherer, where food and other resources are by their nature open-sourced, to agrarian, where wealth is more easily inherited. As suggested by Borgerhoff Mulder et al. [29], the earliest form of effectively heritable material wealth is domestic animals as livestock. Interestingly, it seems that household and farm utensils have much lower inter-generational transmission coefficients than do livestock (see Table 1 in [29]). And even in 'small-scale societies' today (those, sensu Borgerhoff Mulder et al., in which the influence of nation states is limited), livestock are the very stuff of wealth and, along with the land associated with raising it, the means by which wealth is transferred to succeeding generations. These aspects of wealth remain the best predictors of wealth continuity in these societies. This link between domesticates (as wealth) and societal inequality implies that the archeological presence of domesticates can be an important indicator of when inequality of wealth began, and hence indicates the degree of institutional development in the society that left indications of them. If so, we speculate whether the process that Borgerhoff Mulder et al. ([29] and others cited therein) have described, whereby domesticated barnyard stock are at the foundations of modern wealthbased institutions, could logically be extended back in time several thousand years to have its seeds in the domestication of dogs.

Dogs are the only pre-agricultural domesticate [9]. Dogs did not have to be food in order to pay their way. Rather, they paid dividends to their human companions who benefited from channeling the native predatory abilities and territorial proclivities of dogs to increase hunting success and be useful as sentries. And nothing about the small stature that presumably aided a canine peri-domestic life precluded a dog from benefiting the hunt, acting as sentries or as sport. Noting the contemporary success of another small canid in urban settings [31], dogs could be considered the lupine analog of contemporary suburban red foxes, although wolfish sociality may better pre-adapt them to living with people, as distinct from living alongside them as foxes do.

Moreover, as property, dogs are likely to have become status symbols as well as being intrinsically valuable. 


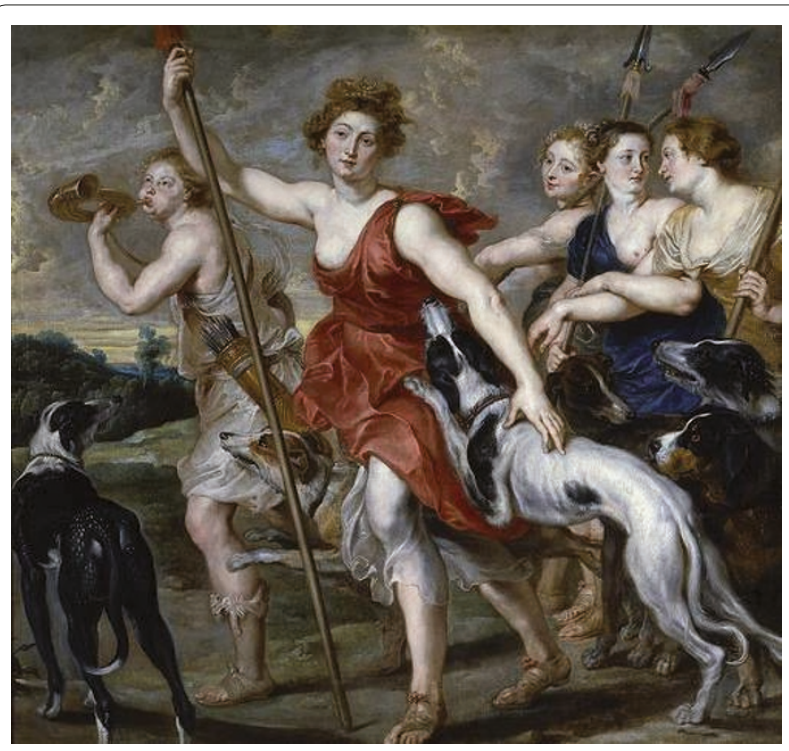

Figure 3. That at least some people, and often trend-setters, have long valued dogs is reflected in their prominence in art from Neolithic times to the present. In this case, Ruebens pictures Diana (Artemis) the goddess of hunting, with a hound center stage.

Indeed, the recent radiation of modern breeds in the Victorian era followed lines of class and wealth, and may be a modern example of the process. Thus, despite the fact that in many contemporary indigenous societies dogs appear to be only loosely owned and little valued, it does not seem implausible that early dogs were valued by their companion humans. Such value would make them objects of inter-generational wealth, and hence qualify as a vehicle for inequality. The fact that contemporary primitive societies often treat dogs badly does not mean that some individuals do (and did) not value them, and to judge by their depictions alongside goddesses like Rubens' Diana (Figure 3), one might guess that some of the people that valued them were trend-setters!

The early value of dogs might take several forms - the fact that the king got the pick of every litter in the ancient Pacific doubtless gave dogs prestige (even if he then ate them) and Margaret Titcomb [32] has it that these early dogs were valued for converting inedible waste into usable protein. Even cultures that are generally unattracted to dogs nonetheless may perceive derived benefits from them. The fact is, people like dogs, and vice versa. Given this, it is not unreasonable to view dogs as wealth perhaps even the first 'living capital'. If dogs are wealth, then, as the earliest domesticate, might not man's best friend also be, ironically, a precursor to (or an indicator of) social inequality in the earliest civilizations.

The accumulating archeological, cultural and genetic evidence emphasizes that wolf domestication cannot be understood outside of the context of early sedentism and civilization. These cultural developments provided the milieu for the interwoven processes of artificial selection and cultural acclimatization that resulted in biological changes leading, in steps, to the dogs of today. This speculation would put dogs at the forefront of the innovations that resulted in the rise and spread of urban life and its sensibilities. Dogs would have been a primer for the notion, crucial to the success of agriculturalism, that individual animals could be chattels, thereby providing society's introduction to dealing with later complexities like the inheritance of livestock and other material goods. Seen in this way, dogs might be harbingers of agriculturalism and the beginning of the end for the hunter-gatherer way, not just legacies of it.

\section{Acknowledgements}

We are grateful to Ray Coppinger, Adam Dutton and Robert Wayne for their insights and comments on an earlier draft, and to Dawn Burnham for her quest for canine art.

\section{Author details}

'Wildlife Conservation Research Unit, The Recanati-Kaplan Centre, Department of Zoology, University of Oxford, Tubney House, Abingdon Road, Tubney, Abingdon OX13 5QL, UK

'Laboratory of Genomic Diversity, Genetics Section, Bldg 560, Rm 11-26, National Cancer Institute-Frederick Cancer Research Facility, Frederick, Maryland 21702-1201, USA

Published: 24 February 2010

\section{References}

1. Clutton-Brock J: The Walking Larder: Patterns of Domestication, Pastoralism, and Predation. London/Boston: Unwin Hyman; 1989.

2. Diamond JM: Guns, Germs, and Steel: The Fates of Human Societies. New York: Norton; 2005.

3. Hemmer $\mathrm{H}$ : Domestication: The Decline of Environmental Appreciation. Cambridge: Cambridge University Press; 1990.

4. Boyko AR, Boyko RH, Boyko CM, Parker HG, Castelhano M, Corey L, Degenhardt JD, Auton A, Hedimbi M, Kityo R, Ostrander EA, Schoenebeck J, Todhunter RJ, Jones P, Bustamante CD: Complex population structure in African village dogs and its implications for inferring dog domestication history. Proc Natl Acad Sci USA 2009, 106:13903-13908

5. Pang JF, Kluetsch C, Zou XJ, Zhang AB, Luo LY, Angleby H, Ardalan A, Ekström C, Sköllermo A, Lundeberg J, Matsumura S, Leitner T, Zhang YP, Savolainen P: $m t D N A$ data indicate a single origin for dogs south of Yangtze River, less than 16,300 years ago, from numerous wolves. Mol Biol Evol 2009, 26:2849-2864.

6. Verginelli F, Capelli C, Coia V, Musiani M, Falchetti M, Ottini L, Palmirotta R, Tagliacozzo A, De Grossi Mazzorin I, Mariani-Costantini R: Mitochondrial DNA from prehistoric canids highlights relationships between dogs and SouthEast European wolves. Mol Biol Evol 2005, 22:2541-2551.

7. Smith BD: The Emergence of Agriculture. New York: WH Freeman; 1995.

8. Driscoll CA, Clutton-Brock J, Kitchener AC, O'Brien SJ: The taming of the cat. SciAm 2009, 300:68-75

9. Driscoll CA, Macdonald DW, O'Brien SJ: From wild animals to domestic pets, an evolutionary view of domestication. Proc Natl Acad Sci USA 2009, 106(Suppl 1):9971-9978.

10. Driscoll CA, Menotti-Raymond M, Roca AL, Hupe K, Johnson WE, Geffen E, Harley EH, Delibes M, Pontier D, Kitchener AC, Yamaguchi N, O'brien SJ, Macdonald DW: The Near Eastern origin of cat domestication. Science 2007, 317:519-523.

11. Clutton-Brock J: A Natural History of Domesticated Mammals. 2nd edn. Cambridge/New York: Cambridge University Press; 1999.

12. Clutton-Brock J: Origins of the domestic dog: domestication and early history. In The Domestic Dog: Its Evolution, Behaviour, and Interactions with People. Edited by Serpell J. Cambridge: Cambridge University Press; 1995:7-20.

13. Gray MM, Sutter NB, Ostrander EA, Wayne RK: The IGF1 small dog haplotype 
is derived from Middle Eastern gray wolves. BMC Biol 2010, 8:16.

14. Macdonald DW: The Velvet Claw: A Natural History of the Carnivores. London: BBC Books; 1993.

15. Wang $X$, Tedford RH, Van Valkenburgh B, Wayne RK: Ancestry - evolutionary history, molecular systematics, and evolutionary ecology of Canidae. In The Biology and Conservation of Wild Canids. Edited by Macdonald DW, Sillero-Zubiri C. Oxford: Oxford University Press; 2004:38-54.

16. Germonpré M, Sablin MV, Stevens RE, Hedges REM, Hofreier M, Stiller M, Després VR: Fossil dogs and wolves from Palaeolithic sites in Belgium, the Ukraine and Russia: osteometry, ancient DNA and stable isotopes. $J$ Archaeol Sci 2009, 36:473-490

17. Davis SJM, Valla FR: Evidence for domestication of the dog 12,000 years ago in the Natufian of Israel. Nature 1978, 276:608-610.

18. Tchernov E, Valla FF: Two new dogs, and other Natufian dogs, from the southern Levant. J Archaeol Sci 1997, 24:65-95.

19. Clutton-Brock J: The process of domestication. Mammal Rev 1992, 22:79-85.

20. Serpell J: Pet-keeping and animal domestication: a reappraisal. In The Walking Larder: Patterns of Domestication, Pastoralism, and Predation. Edited by Clutton-Brock J. London: Unwin; 1989:10-21.

21. Coppinger R, Coppinger L: Dogs: A Startling New Understanding of Canine Origin, Behavior, and Evolution. New York: Scribner; 2001.

22. Macdonald DW, Carr GM: Variation in dog society: between resource dispersion and social flux. In The Domestic Dog, Its Evolution, Behaviour and Interactions with People. Edited by Serpell J. Cambridge: Cambridge University Press; 1995:199-216

23. Moehrenschlager A, List R, Macdonald DW: Escaping intraguild predation: Mexican kit foxes survive while coyotes and golden eagles kill Canadian swift foxes. J Mammal 2007, 88:1029-1039.

24. Musiani M, Leonard JA, Cluff HD, Gates CC, Mariani S, Paquet PC, Vilas C, Wayne RK: Differentiation of tundra/taiga and boreal coniferous forest wolves: genetics, coat colour and association with migratory caribou. Mo
Ecol 2007, 16:4149-4170.

25. Davis S J M, Valla VR, Francois R: Evidence for domestication of the dog 12,000 years ago in the Natufian of Israel. Nature 1978, 276: 608-610.

26. Tchernov E, Valla VR: Two new dogs, and other Natufian dogs, from the southern Levant. J Archaeol Sci 1997, 24:65-95.

27. Akey JM, Ruhe AL, Akey DT, Wong AK, Connelly CF, Madeoy J, Nicholas TJ, Neff $M W$ : Tracking footprints of artificial selection in the dog genome. Proc Natl Acad SciU S A 2010, 107:1160-1165.

28. Parker HG, Kim LV, Sutter NB, Carlson S, Lorentzen TD, Malek TB, Johnson GS, DeFrance HB, Ostrander EA, Kruglyak L: Genetic structure of the purebred domestic dog. Science 2004, 304:1160-1164.

29. Borgerhoff Mulder M, Bowles S, Hertz T, Bell A, Beise J, Clark G, Fazzio I, Gurven M, Hill K, Hooper PL, Irons W, Kaplan H, Leonetti D, Low B, Marlowe F, McElreath R, Naidu S, Nolin D, Piraino P, Quinlan R, Schniter E, Sear R, Shenk M, Smith EA, von Rueden C, Wiessner P: Intergenerational wealth transmission and the dynamics of inequality in small-scale societies. Science 2009, 326:682-688.

30. Acemoglu D, Robinson J: Foundations of societal inequality. Science 2009, 326:678-679.

31. Macdonald DW: Running with the Fox. New York: Facts on File Publications; 1987.

32. Titcomb M: Dogs and Man in the Ancient Pacific with Special Attention to Hawaii. Honolulu, HI: Star-Bulletin Print Co.; 1969. [Bernice P. Bishop Museum Special Publication, volume 59]

doi:10.1186/jbiol226

Cite this article as: Driscoll CA, Macdonald DW: Top dogs: wolf

domestication and wealth. Journal of Biology 2010, 9:10. 